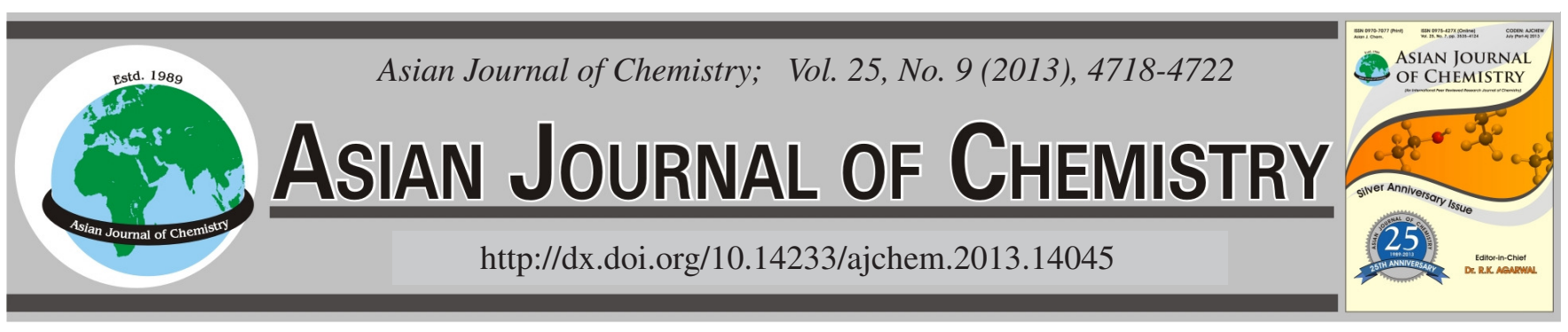

\title{
Study of Tannery Phase Diagram of Rotenone Derris elliptica (Fabales: Fabaceae): A Novel Approach of Insecticide Formulation
}

\author{
S.N.B. Ahmad ${ }^{1}$, M.T. Islam ${ }^{1, *}$, D.K. AbDUllah ${ }^{2}$ and D. OMar ${ }^{1}$
}

${ }^{1}$ Department of Plant Protection, Faculty of Agriculture, University Putra Malaysia, 43400 Serdang, Selangor, Malaysia

${ }^{2}$ Department of Chemistry, Faculty of Science, Universiti Putra Malaysia, 43400 Serdang, Selangor, Malaysia

*Corresponding author: Fax: +60 3 89464151; Tel: +60 3 89464172; E-mail: islamtuhin@yahoo.com

(Received: 10 May 2012;

Accepted: 4 March 2013)

AJC-13056

The present study was conducted for evaluating the tannery phase diagram of microemulsion formulation of rotenone. In this paper,
oil-in-water microemulsions were obtained by the titration method through ternary phase diagram study. The widest oil-in-water
microemulsion region ( $48 \%$ isotropic area) in phase diagram system was obtained in Tween 20/Agnique BL 7001/water system compared
with others, while the narrowest oil-in-water microemulsion region ( $6 \%$ isotropic area) was obtained in Agnique PG 9116/Edenor ME/
water system. This novel approach for insecticide formulation of rotenone might be useful for the control of insect. This study will
provide the maximum utilization of botanical insecticide concerning environmental friendly strategy.

Key Words: Microemulsion, Derris elliptica, Insecticide formulation, Isotropic area, Titration.

\section{INTRODUCTION}

Rotenone is a bio-active compound that has a strong paralysis action (knock-down effect) on cold-blooded animals and used as an insecticide to combat pests ${ }^{1}$. Pest species controlled by rotenone include aphids, caterpillars, beetles and various aquatic larvae. The use of agro-based materials in the pesticide formulation has become more important, because, they are relatively biodegradable, low toxicity and renewable resources than those from mineral oil derived commodities ${ }^{2}$. Currently, the most studies on pesticide formulation are more focused on herbicides and not much information is available on insecticide formulations and their efficacy study. The use of biodegradable insecticides in crop protection is a practical sustainable alternative to the synthetic organic-based insecticides and they could maintain biological diversity of predators, reduces environmental contamination and human health hazards ${ }^{3}$.

As a new environment-friendly pesticide formulation to replace the traditional ones like emulsifiable concentrate and to decrease the content of the organic solvent in the formulation, the content of surfactants will be reduced and the dosage of pesticide active ingredient will be increased as much as possible in the new formula design. Beside this, it is also a basic requirement for the design of pesticide formulation to form a thermodynamic stabilized microemulsion when diluted with water at practice use ${ }^{4}$. Despite the significance of agro- chemicals use for pest control, the environmental problems caused by over use of agrochemicals have brought scientists and publics much concern in recent years ${ }^{5}$. Thus, formulation scientists now are facing the challenge to explore novel green or environmental friendly agrochemical formulation to improve the biological efficacy and develop technique that can be employed to reduce pesticide use while maintaining plant protection.

Microemulsions are currently the subject of many investigations because of their wide range of potentiality and utilization $^{6}$. It is composed of oil phase, surfactant and aqueous phase at appropriate ratios ${ }^{7}$. It has several specific physicochemical properties such as transparency, optical isotropy, low viscosity and thermodynamic stability ${ }^{8,9}$. There has been considerable interest in many applications of microemulsion in a variety of chemical and industrial processes, such as pharmaceutics, cosmetics, especially agrochemicals. Therefore, for successful establishment of microemulsion formulation of rotenone and to reduce insecticidal load in the environment, the role of this plant extract is very important. Keeping this view, the present study was conducted for evaluating the tannery phase diagram of microemulsion formulations of rotenone.

\section{EXPERIMENTAL}

The experiment was conducted in the Laboratory of Toxicology, Department of Plant Protection, Faculty of Agriculture, University Putra Malaysia. The present study was 
TABLE-1

COMPOUND USED IN TERNARY PHASE DIAGRAM STUDY

\begin{tabular}{llcc}
\hline Compounds & Trade name & \% a.i. ${ }^{1}$ & Class \\
\hline Surfactant- & & & \\
Alkyl polyglycoside & Agnique PG 8107-U & $68-72$ & Surfactant \\
Alkyl polyglycoside & Agnique PG 9116 & $48-52$ & Surfactant \\
Polyoxyethylene sorbitan monolaurate & Tween 20 & N.A. & Surfactant \\
Oil/Carrier- & & & \\
Palmitic acid-oleic acid Methyl ester & Edenor ME (ME C18-70U MY) & N.A. & Adjuvant \\
Methyl ester and fatty alcohol (blended) & Agnique BL 7001 & N.A. & Adjuvant \\
Methyl ester and fatty alcohol (blended) & Agnique BL 7002 & N.A. & Adjuvant \\
Xylene & Xylene & 99.8 & Solvent \\
Rotenone (CLCE) & N.A. & 1.15 & Insecticide \\
\hline${ }^{1}$ a.i Active ingredient and N. A. = Not available & & &
\end{tabular}

carried out under laboratory conditions (temperature $26 \pm 2{ }^{\circ} \mathrm{C}$, RH $65 \pm 5 \%$ and photoperiod $12 \mathrm{~h} \mathrm{L:} 12 \mathrm{~h} \mathrm{D})$. Two alkyl polyglycoside surfactants, Agnique PG 8107-U and Agnique PG 9116 were obtained from Cognis Oleochemical (M) Sdn. Bhd, Tween 20 was purchased from Sigma-Aldrich Inc., USA. Palm oil based carrier, Edenor ME, Agnique BL 7001 and Agnique BL 7002 were obtained from Cognis Oleochemical (M) Sdn. Bhd, while xylene was purchased from Merck KGaA, Germany.

The rotenone was concentrated liquid crude extract from Derris elliptica (Fabales: Fabaceae) and supplied by Chemical Engineering Pilot Plant, University Technology of Malaysia. The brief description, characteristic and source on inert and active materials were showed in Table- 1 . The microemulsions were prepared at room temperature $\left(26 \pm 1^{\circ} \mathrm{C}\right)$ using aqueous titration method ${ }^{10}$. The ratio of surfactant and oil in experimental mixture was fixed as 9 combinations; 10:90, 20:80, 30:70, 40:60, 50:50, 60:40, 70:30, 80:20 and 90:10. Appropriate amounts of surfactant and oil were weighed for a total of $0.5 \mathrm{~g}$ into $10 \mathrm{~mL}$ culture glass tube with cap. Sample was shaken for sufficient time to attain equilibrium. Water was added by titrating into the oil and surfactant mixture at which transition occurred were used to determine the phase domains. Each sample was assessed visually for spontaneous emulsification through clarity, stability and transparency. The ratio of water, oil and surfactant obtained was mark on three axis ternary phase diagram and similar procedure was repeated to other oil and surfactant ratios (Table-2). Those point which joint together indicated the isotropic area of microemulsion in the 3 component phase diagram systems. Samples which retained transparent one-phase appearance were kept at room temperature for 4 weeks to indicate the stability of a microemulsion ${ }^{11}$. The results obtained from the experiment were used to plot ternary phase diagram. The phase diagram consisted of water phase, second presenting surfactant and third representing oil.

\section{RESULTS AND DISCUSSION}

The phase diagram showed the occurrence of one phase isotropic area with Agnique PG 8107-U as surfactant (Fig. 1A). The narrow isotropic region obtained in this system revealed that Agnique PG 8107-U was not easily dissolved (Table-3). The microemulsions began to form when water was added to the system. Mixture of Edenor ME/Agnique PG 8107-U at ratio 5/95 was found to assist solubilization of Edenor ME in
TABLE-2

SURFACTANTS, OILS AND AQUEOUS PHASE GROUPED IN DIFFERENT COMBINATIONS FOR PHASE DIAGRAM CONSTRUCTION

\begin{tabular}{cllc}
\hline Group & Surfactant phase & Oil phase & Aqueous phase \\
\hline 1 & Agnique PG 8107-U & Edenor ME & Water \\
2 & Agnique PG 8107-U & Xylene & Water \\
3 & Agnique PG 8107-U & Agnique BL 7001 & Water \\
4 & Agnique PG 8107-U & Agnique BL 7002 & Water \\
5 & Agnique PG 9116 & Edenor ME & Water \\
6 & Agnique PG 9116 & Xylene & Water \\
7 & Agnique PG 9116 & Agnique BL 7001 & Water \\
8 & Agnique PG 9116 & Agnique BL 7002 & Water \\
9 & Tween 20 & Edenor ME & Water \\
10 & Tween 20 & Xylene & Water \\
11 & Tween 20 & Agnique BL 7001 & Water \\
12 & Tween 20 & Agnique BL 7002 & Water \\
\hline
\end{tabular}

TABLE-3

PERCENTAGE OF ISOTROPIC AREA IN PHASE DIAGRAM SYSTEM ACCORDING TO THE DECREASING ORDER

\begin{tabular}{lc}
\hline Phase diagram & $\begin{array}{c}\text { Total one phase } \\
\text { isotropic area (\%) }\end{array}$ \\
\hline Tween 20/Agnique BL 7002/water & 48 \\
Tween 20/Agnique BL 7001/water & 45 \\
Tween 20/Edenor ME/water & 31 \\
Agnique PG 9116/Agnique BL 7001/water & 26 \\
Agnique PG 8107-U/Agnique BL 7001/water & 24 \\
Agnique PG 8107-U/Agnique BL 7002/water & 24 \\
Tween 20/xylene/water & 23 \\
Agnique PG 9116/Agnique BL 7002/water & 17 \\
Agnique PG 9116/xylene/water & 15 \\
Agnique PG 8107-U/xylene/ water & 14 \\
Agnique PG 8107-U/Edenor ME/water & 10 \\
Agnique PG 9116/Edenor ME/water & 6 \\
\hline
\end{tabular}

water. The continuous addition of water to the transparent solution gradually changes to two-phase solution at ratio 8/92 of Edenor ME/Agnique PG 8107-U. Narrow isotropic region was obtained in range 1-18\% w/w of xylene composition (Fig. 1B); and in Agnique PG 9116/Edenor ME/water system (Fig. $1 \mathrm{E})$. At $50 \% \mathrm{w} / \mathrm{w}$ water, it was observed that microemulsion was formed with $7 \%$ w/w xylene and $44 \%$ w/w Agnique PG 8107-U composition (Fig. 1B). The microemulsion region increased with increasing of Agnique PG 9116 (>96\% w/w) content in the system. After titration of water at $95 \% \mathrm{w} / \mathrm{w}$ and $5 \%$ w/w of Agnique PG 9116 and Edenor ME, the transition from turbid to transparent solution were observed after the weight fraction of water was above $24 \% \mathrm{w} / \mathrm{w}$ and the 
microemulsion region began to decrease (Fig. 1E). The existence of microemulsion regions in the systems prepared using Agnique BL 7001 and Agnique PG 8107-U in which the aqueous phases were $94 \%$ w/w of water (Fig. 1C). A sharp end of isotropic region was produced near the Agnique BL 7001 corner at $57 \%$ w/w of Agnique BL 7001 and $46 \%$ w/w of Agnique PG 8107$\mathrm{U}$ (Fig. 1D). The microemulsion region was produced at high concentration of Agnique PG 9116 (above $84 \%$ w/w) (Fig. 1F). A minimum microemulsion region obtained at ratio $85 / 15$ of Agnique PG 9116/xylene towards water corner.

A wider microemulsion region obtained in Agnique PG 9116/Agnique BL 7001/ water (Fig. 1G); Agnique PG 9116/ Agnique BL 7002/water (Fig. 1H); and Tween 20/Agnique BL 7002/water system (Fig. 1L). The transparent region stretched up to $65 \%$ w/w of Agnique PG 9116 towards the water corner. The diagram of Tween 20/Edenor ME/water system showed that the system containing Tween 20 as surfactant has a wider microemulsions region compared with Agnique PG 8107-U and Agnique PG 9116 systems (Fig. 1I). The wider isotropic region was produce until it reached 60/40 of Tween 20/xylene ratio before water addition (Fig. 1J). After additional of water, the isotropic region spread on the Tween 20 corner and began to decrease until minimum of $8 \% \mathrm{w} / \mathrm{w}$ xylene. The isotropic region has increased at $13 / 39 \% \mathrm{w} / \mathrm{w}$ of xylene/Tween 20 before it began to decrease towards the water corner. A one-phase microemulsion system was not existed above $37 \%$ and $63 \%$ w/w Tween 20 and xylene ratio (Fig. 1J). An outline of the composition internal structures of a microemulsion system were illustrated (Fig. 1K). A small curve formed between these lines caused non isotropic area that gave a unique pattern of the isotropic region (Fig. 1K). On dilution of solutions having different oil/ surfactant ratios with the aqueous phase, one-phase transparent solutions were showed the special appearance of isotropic area observed in this diagram (Fig. 1K). Microemulsions could only be formed on dilution of an oil-surfactant mixture with water ${ }^{12}$.

A small isotropic jelly-like area was observed in the middle of shaded area that might effect of unknown interaction caused by surfactant, oil and water (Fig. 1L). The maximum water can be diluted at ratio 20/80 of Agnique BL 7001/ Tween 20 was $23 \%$ w/w (Fig. 1L). This observation revealed that at this jelly-like area, microemulsion formulation cannot be formulated because of highly viscous properties that might not suitable for liquid spray application. The relationship between the water-poor and the water-rich regions in phase diagrams above may be predicted that the microemulsion structure was vary greatly, but progressively, as the composition varies over such a wide range as mentioned previously ${ }^{13}$. The widest o/w microemulsion region $(48 \%)$ in phase diagram system was obtained in Tween 20/Agnique BL 7001/water system
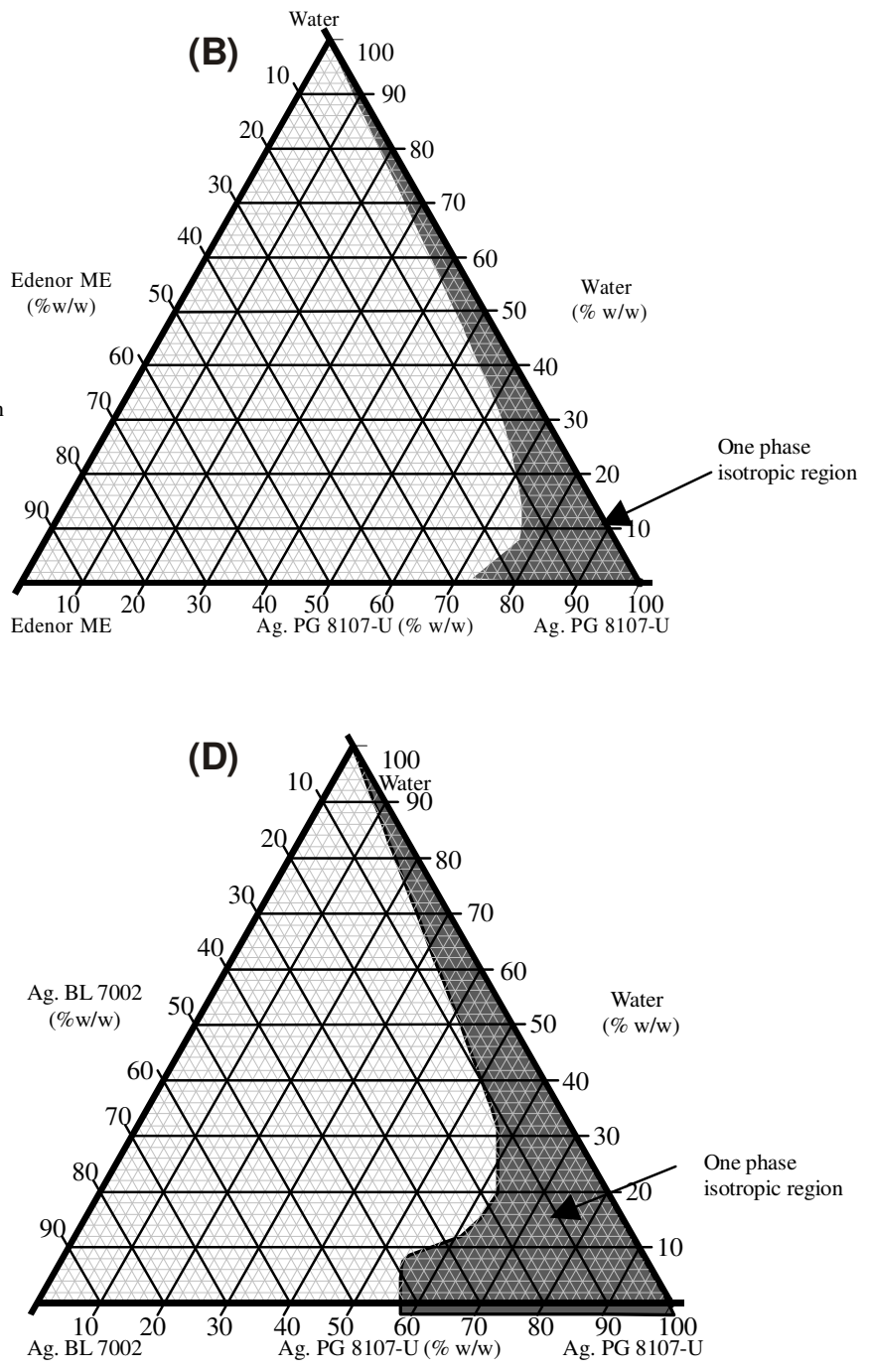

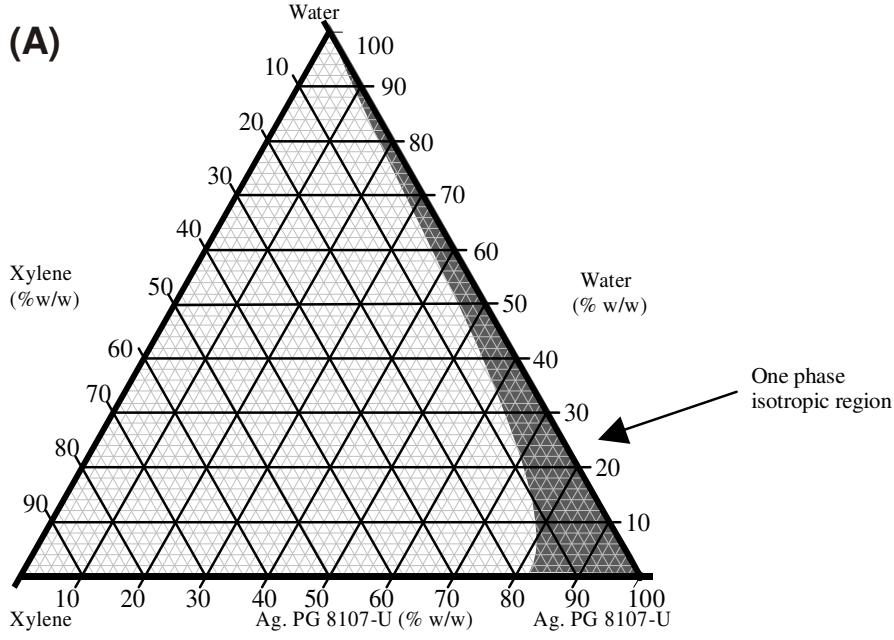

(C)

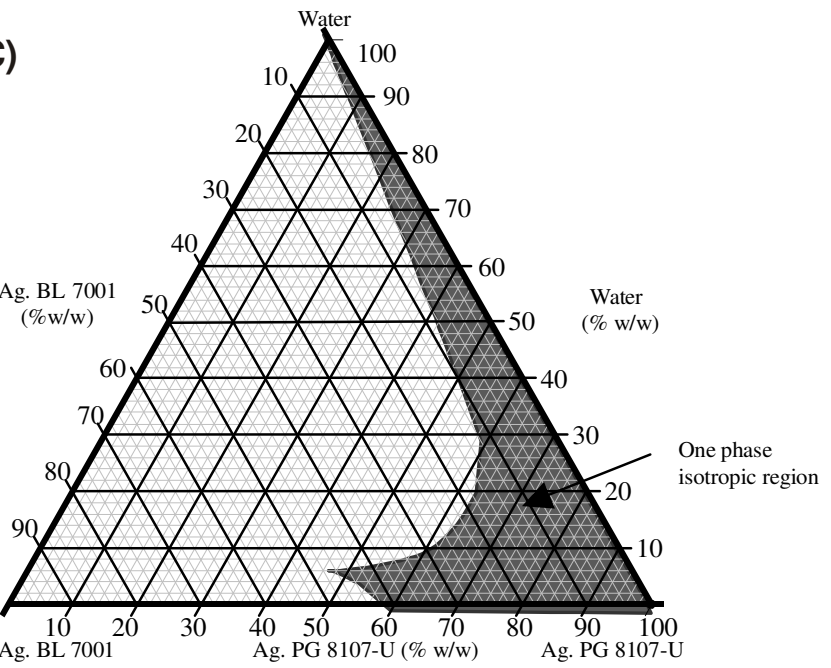



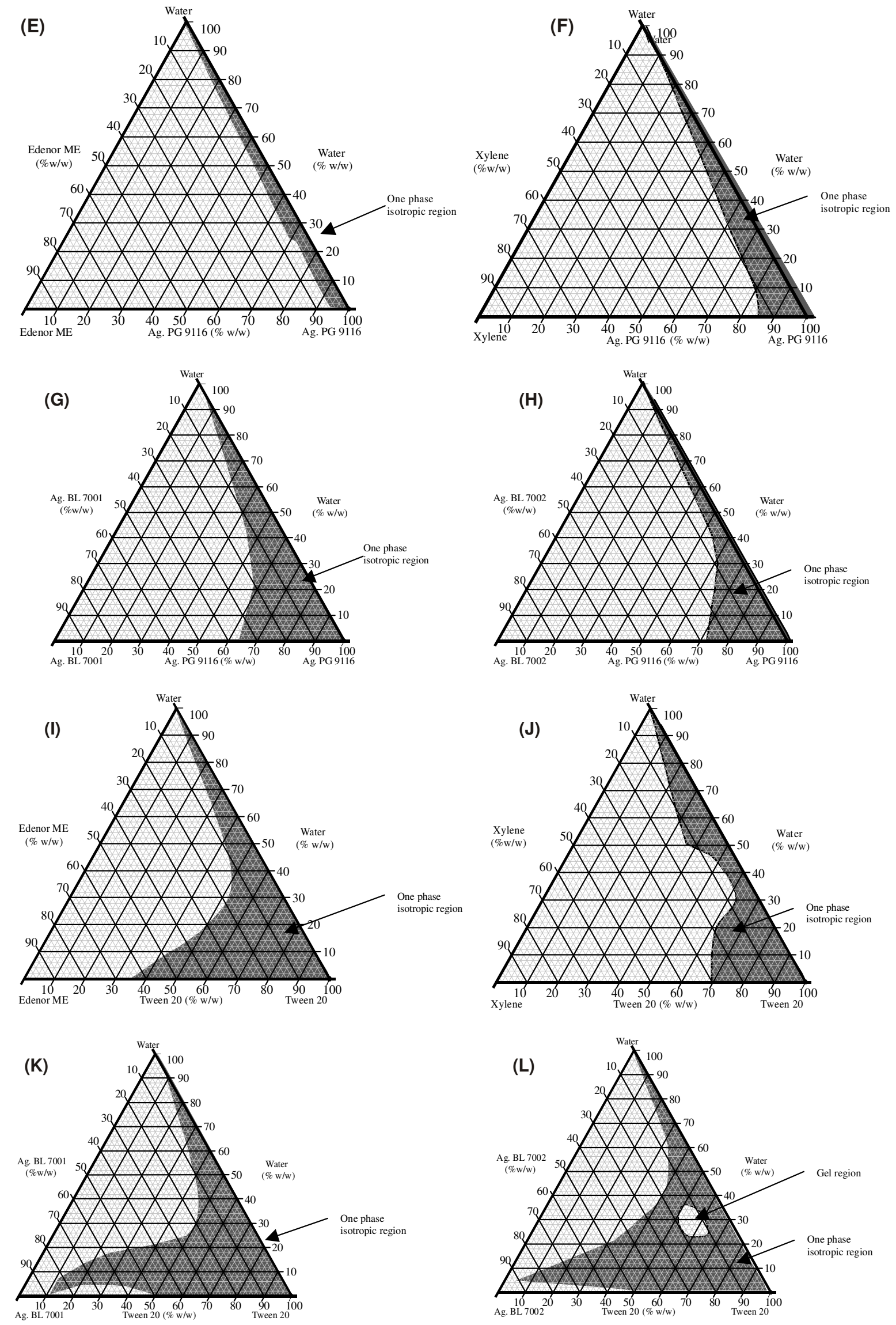

Fig. 1. Phase diagram system containing (A) Edenor ME/Agnique PG 8107-U/water, (B) Agnique PG 8107-U/xylene/water, (C) Agnique PG 8107-U/ Agnique BL 7001/water, (D) Agnique PG 8107-U/Agnique BL 7002/water, (E) Agnique PG 9116/Edenor ME/water, (F) Agnique PG 9116/xylene/ water, (G) Agnique PG 9116/Agnique BL 7001/water, (H) Agnique PG 9116/Agnique BL 7002/water, (I) Tween 20/Edenor ME/water, (J) Tween 20/ xylene/water, (K) Tween 20/Agnique BL 7001/water and (L) Tween 20/Agnique BL 7002/water 
compared with others, while the narrowest was Agnique PG 9116/Edenor ME/water (6\% isotropic area) (Table-3). The widest isotropic area of system containing alkyl polyglycoside surfactant was Agnique PG 9116/Agnique BL 7001/water which produce $26 \%$ isotropic area (Table-3). In this study, all alkyl polyglycosides used (Edenor ME, Agnique BL 7001 and Agnique BL 7002) gave the greater microemulsion region in all phase diagrams compared with xylene.

\section{Conclusion}

In order to formulate microemulsion of rotenone for insecticidal purpose, it is necessary to choose microemulsion area in phase diagram that form over a wide range of oil, surfactant and water composition. The solution in transparent region might be useful to formulate microemulsion. This novel approach for insecticide formulation of rotenone might be useful for the control of insect that will provide the maximum utilization of botanical insecticide concerning environmental friendly strategy.

\section{ACKNOWLEDGEMENTS}

This research was funded by Grant No. 01-01-07-082FR from the Fundamental Research Grant Scheme (FRGS), Ministry of Higher Education, Malaysia.

\section{REFERENCES}

1. T.V. Andel, Econ. Botany, 54, 500 (2000).

2. P.N.P. Chow and C.A. Grant, in ed.: C.L. Foy, Research and Development of Agro-adjuvant: A Bibliographic Survey in Adjuvant for Agrochemical, CRC Press Boca Raton, Florida, pp. 3-15 (1992).

3. N. Grange and S. Ahmed, Handbook of Plants with Pest Control Properties, John Wiles and Sons, New York (1998).

4. J.L. Zhu, K. Zhang and Z.H.G. Cui, China Surf. Deterg. Cosm., 32, 43 (2002).

5. D. Pimentel, Techniques for Reducing Pesticide Use, Wiley, New York (1997).

6. R. Zana, Heterog. Chem. Rev., 1, 145 (1994).

7. M. Changez and M. Varshney, Drug Dev. Ind. Pharm., 26, 507 (2000).

8. B. Baroli, M.A. Lopez-Quintela, M.B. Delgado-Charro, A.M. Fadda and J. Blanco-Mendez, J. Control. Rel., 69, 209 (2000).

9. M.J. Lawrence and G.D. Rees, Adv. Drug Deliv. Rev., 45, 89 (2000).

10. S. Shafiq, F. Shakeel, S. Talegaonkar, F.J. Ahmad, R.K. Khar and M. Ali, Eur. J. Pharm. Biopharm., 66, 227 (2007).

11. J. Flanagan, K. Kortegaard, D.N. Pinder, T. Rades and H. Singh, Food Hydrocoll., 20, 253 (2006).

12. A. Forgiarini, J. Esquena, C. Gonzalez and C. Solans, Langmuir, 17, 2076 (2001).

13. M. Trotta, R. Cavalli, E. Ugazio and M.R. Gasco, Int. J. Pharm., 143, 67 (1996). 